\title{
Aquatic Toxicity Comparison of Silver Nanoparticles and Silver Nanowires
}

\author{
Eun Kyung Sohn, ${ }^{1}$ Seyed Ali Johari, ${ }^{2}$ Tae Gyu Kim, ${ }^{1}$ Jin Kwon Kim, ${ }^{1}$ Ellen Kim, \\ Ji Hyun Lee, ${ }^{1}$ Young Shin Chung, ${ }^{1}$ and Il Je Yu ${ }^{1}$ \\ ${ }^{1}$ Institute of Nanoproduct Safety Research, Hoseo University, Asan, Republic of Korea \\ ${ }^{2}$ Fisheries Department, Natural Resources Faculty, University of Kurdistan, P.O. Box 416, Sanandaj 66177-15175, Iran
}

Correspondence should be addressed to Il Je Yu; u1670916@chollian.net

Received 9 November 2014; Accepted 8 January 2015

Academic Editor: Masood Ahmad

Copyright (c) 2015 Eun Kyung Sohn et al. This is an open access article distributed under the Creative Commons Attribution License, which permits unrestricted use, distribution, and reproduction in any medium, provided the original work is properly cited.

\begin{abstract}
To better understand the potential ecotoxicological impact of silver nanoparticles (AgNPs) and silver nanowires (AgNWs) released into freshwater environments, the toxicities of these nanomaterials were assessed and compared using Organization for Economic Cooperation and Development (OECD) test guidelines, including a "Daphnia sp., acute immobilization test," "Fish, acute toxicity test," and "freshwater alga and cyanobacteria, growth inhibition test." Based on the estimated median lethal/effective concentrations of AgNPs and AgNWs, the susceptibility to the nanomaterials was different among test organisms (daphnia $>$ algae $>$ fish), suggesting that the AgNPs are classified as "category acute 1" for Daphnia magna, "category acute 2" for Oryzias latipes, and "category acute 1" for Raphidocelis subcapitata, while the AgNWs are classified as "category acute 1" for Daphnia magna, "category acute 2" for Oryzias latipes, and "category acute 2" for Raphidocelis subcapitata, according to the GHS (Globally Harmonized System of Classification and Labelling of Chemicals). In conclusion, the present results suggest that more attention should be paid to prevent the accidental or intentional release of silver nanomaterials into freshwater aquatic environments.
\end{abstract}

\section{Introduction}

The number of engineered nanomaterial (NM) products is increasing in many industrial fields, and large quantities of NM are being released, and eventually entered into the environment. Keller et al. [1] estimated that $63-91 \%$ of over 260,000-309,000 metric tons of NMs produced globally in 2010 was ended up in landfills, while the balance was released into soil $(8-28 \%)$, water bodies $(0.4-7 \%)$, and atmosphere (0.1-1.5\%). Among many different types of NMs, nanoscale silver has been regarded as one of the most important nanomaterials because of its unique properties and ability to form diverse nanostructures, and thus is placed in the list of consumer product inventories [2]. Annually about 63 tons of nanosilver are expected to enter water bodies on a worldwide basis [1] and the concentration in aqueous environments has been predicted to range from 0.03 to 0.32 micrograms per liter [3]. Therefore, understanding the potential harmful effects of nanosilver on aquatic organisms is particularly of importance.
Although silver nanoparticles (AgNPs) and silver nanowires (AgNWs) are basically synthesized from the silver element, their applications in consumer products are different according to their unique properties. The antimicrobial properties of AgNPs are the main reason for their extensive use [4], while the high electrical and thermal conductivities of AgNWs have led to their application in many consumer products such as conductive inks, transparent films, conductive polymer composites, and coatings. In addition, AgNWs possess an effective antimicrobial capability [5].

Although many studies have already investigated the toxic effects of AgNPs in several aquatic organisms such as fish [6], Daphnia [7], and algae [8], limited information is currently available on the aquatic toxicity of AgNWs. George et al. [9] demonstrated that Ag nanoplates showed a higher level of toxicity to the rainbow trout gill epithelial cell line and zebrafish embryos when compared to nanospheres and NW in spite of the lower rates of dissolution and bioavailability of this material shape. Also, Kim et al. [10] investigated the 
gender-specific accumulation of AgNPs in kidneys of Fischer 344 rats, and Artal et al. [11] showed that the acute toxicity of silver vanadate nanowires decorated with AgNPs to Daphnia similis was due to the $\mathrm{Ag}^{+}$released from nanomaterials trapped in the gut, along with the Ag released into the test media. Finally, Scanlan et al. [12] recently compared the toxicities of silver ions and nanowires and found that some AgNWs were highly toxic to D. manga, yet less toxic than ionic silver. The toxicity of AgNWs varied as a function of their dimensions, coating, and solution chemistry.

Accordingly, the present study investigated the aquatic toxicity of AgNWs (as one-dimensional (1D) silver nanostructure) to three model aquatic organisms, including a fish (Oryzias latipes), crustacean (Daphnia magna), and algae (Raphidocelis subcapitata) according to the Organization for Economic Cooperation and Development (OECD) test guidelines, and compared with the aquatic toxicity of AgNPs (as zero-dimensional (0D) silver nanostructure). The results of study could provide valuable information about potential AgNWs toxicity to aquatic organisms, which might be useful for assessing ecological risk of AgNWs.

\section{Materials and Methods}

2.1. Nanomaterials and Characterization. The colloidal AgNPs were purchased from ABC Nanotech Co. Ltd. (Daejeon, Korea). According to information provided by the manufacturer, it contained 20 21 wt\% citrate as a capping agent of AgNPs with a diameter range of 5-25 nm. The AgNWs suspension was purchased from Sigma Aldrich (St. Louis, USA), and according to information provided by the manufacturer, it contained $0.5 \mathrm{wt} \%$ AgNWs in isopropanol with a diameter of $60 \pm 10 \mathrm{~nm}$ and length of $10 \pm 5 \mu \mathrm{m}$. Size distribution of silver nanomaterials (AgNMs) was obtained using dynamic light scattering (DLS) and transmission electron microscope (TEM). DLS provides hydrodynamic size as well as size distribution of nanoparticles in liquid medium. The DLS measurement was conducted with a Nanophox (Sympatec, Clausthal-Zellerfeld, Germany) at $25^{\circ} \mathrm{C}$ with a complex refraction index of 1.33 and a viscosity of $0.89 \mathrm{mPas}$. DLS measures the scattering intensity $I(q, t)$ of a sample's Brownian motion, and the autocorrelation function is acquired from $G_{2}(\tau)=\langle I(0) I(\tau)\rangle=1 / T \int I(t) I(t+\tau) d t$. When $b$ is the experimental constant, the relationship of the normalized first-order autocorrelation function $G_{1}(\tau)$ is estimated by $G_{2}(\tau)=1+b\left|G_{1}(\tau)\right|^{2} . G_{1}(\tau)$ is then connected to the diffusion constant $D, G_{1}(\tau)=\exp \left(-2 q^{2} D t\right)$, where $q=\left(4 p n / l_{0}\right) \sin (q / 2)$. In this equation, $n, l_{0}$, and $q$ are the refractive index of the solution, wavelength of the incident light, and scattering angle, respectively. The sample size was estimated using the Einstein-Stokes relation, $D=k_{B} T / 6 p h r$, where $k_{B}, T$, and $r$ are the Boltzmann factor, temperature, and hydrodynamic radius of the samples [13].

The TEM analysis of the AgNMs was performed using a field emission-transmission electron microscope (FE-TEM, JEM2100F, JEOL, Tokyo, Japan) with an acceleration voltage of $200 \mathrm{kV}$. Using photographs at a magnification of 100,000, the dimensions of 272 randomly selected AgNPs and 471 randomly selected AgNWs were measured. In addition, the EDX analysis of the AgNMs was performed using an energydispersive X-ray spectrometer (EDS, TM200, Oxford, UK). TEM samples were prepared as diluted using DI water.

2.2. Silver Concentration in Test Suspension. The actual concentrations of silver in the fish toxicity suspension were analyzed using an atomic absorption spectrophotometer equipped with a Zeeman graphite furnace (Perkin Elmer 5100ZL, Zeeman Furnace Module, USA) based on the NIOSH 7300 method [14].

2.3. Fish Toxicity Tests. Three-month Oryzias latipes juveniles with a mean total body weight of $0.39 \pm 0.01 \mathrm{~g}$ (mean \pm SD) and mean total body length of $2.62 \pm 0.05 \mathrm{~cm}$ (mean \pm $\mathrm{SD})$ were used for the toxicity experiments. Prior to the experiments, fish were kept in $100 \mathrm{~L}$ tanks with a water circulation system and 16/8 hour light and dark cycle and were fed pellet feed (TOPMEAL) at $1 \%$ of their body weight. After 7 days of adaptation, fish were transferred to separate test vessels with a volume of $10 \mathrm{~L}$ and allowed to adapt for a further $24 \mathrm{hrs}$ prior to starting the toxicity experiments. Dechlorinated tap water was used for all experiments (dechlorination performed by vigorous aeration for at least $48 \mathrm{hrs}$ ). To avoid overestimating the toxicity, the feeding of the fish was stopped 48 hrs before starting the experiments in order to minimize the risk of AgNMs absorption in the fecal material or food and minimize the dissolved organic carbon (DOC) in the exposure tanks [15].

The acute $(96 \mathrm{hrs})$ toxicity tests were conducted on fish in accordance with standard OECD guideline number 203 (Fish, acute toxicity test) [16]. A series of preliminary experiments $(10,1,0.1$, and $0.01 \mathrm{mg} / \mathrm{L})$ was conducted to determine the range of AgNMs concentrations that produced mortality of the fish. As a result, nominal concentrations of 10, 5, $2.5,1.25,0.625$, and $0.312 \mathrm{mg} / \mathrm{L}$ were selected as effective concentrations for performing the main toxicity tests of each chemical. The fish were exposed to the AgNMs based on a static exposure regime. For every experiment, 7 healthy fishes were directly transferred into each prepared concentration. Control groups (7 fishes) were also included for each treatment. An additional vehicle control group containing isopropyl alcohol (IPA, $0.2 \%$ ) was included along with the AgNWs experiments. The mortalities were recorded at 24, 48,72 , and 96 hours postexposure and the $\mathrm{LC}_{50}$ values were calculated using a probit analysis (PASW statistics 18, 2009, SPSS INC, Chicago, IL).

2.4. Daphnia Toxicity Tests. The acute $(48 \mathrm{~h})$ toxicity tests were conducted on neonate Daphnia magna (younger than $24 \mathrm{hrs}$ old) in accordance with standard OECD guideline number 202 (Daphnia Sp. acute immobilization test) [17]. Here, fully aerated M4 media were used as the exposure media and the test solutions were prepared immediately before use by diluting appropriate amounts of the AgNMs in the M4 media. All tests were conducted in a water bath system with a constant temperature $\left(21.45 \pm 0.10^{\circ} \mathrm{C}\right)$ and $16 / 8 \mathrm{hrs}$ light dark cycle. In the experiments, dissolved oxygen, $\mathrm{pH}$, 
hardness, and alkalinity of exposure media (mean \pm SD) were $4.87 \pm 0.14 \mathrm{mg} / \mathrm{L}, 7.47 \pm 0.01,140 \mathrm{mg} / \mathrm{L}$, and $230 \mathrm{mg} / \mathrm{L}$, respectively. Since the presence of algae was shown to affect the toxicity of AgNPs [18] and presence of organic matter found to inhibit the Ag ion uptake by Daphnia [19], animals were not fed during the experiments.

A series of preliminary experiments $(1,0.1,0.01$, and $0.001 \mathrm{mg} / \mathrm{L}$ ) was conducted to determine the concentration ranges of each AgNM that produced immobility of D. magna. According to the determined concentration ranges, effective concentrations were then selected $(0.0161,0.0115,0.0082$, 0.0059. 0.0042, and 0.0030 mg/L for AgNPs; 0.32, 0.16, 0.08, $0.04,0.02,0.01$, and $0.005 \mathrm{mg} / \mathrm{L}$ for AgNWs). The neonates were exposed to each AgNM in four repeats (5 neonates per replicate) based on a static exposure regime in $100 \mathrm{~mL}$ of the exposure media in glass exposure beakers. Control groups (5 neonates in four repeated) were also included for each treatment. An additional vehicle control group containing isopropyl alcohol (IPA, 0.24\%) was included in the AgNWs experiments. After 24 and $48 \mathrm{hrs}$ of exposure, immobilization and mortality of the Daphnia were assessed in each test beaker. According to Annex 1 of OECD guideline number 202, an animal was recorded as dead when it was immobile, that is, not able to swim or no observed movement of appendages or the postabdomen within $15 \mathrm{sec}$ after agitation of the test container [17]. Furthermore, the live Daphnia were categorized according to their swimming type: normal swimming (NOR), abnormal swimming $(\mathrm{ABN})$, erratic swimming (ERR), Daphnia mainly at the bottom (BOT), and Daphnia mainly at the surface (SUR) [7]. Any visible uptake or adsorption of NM by the D. magna was also monitored and recorded. The $\mathrm{EC}_{10}, \mathrm{EC}_{50}$, and $\mathrm{EC}_{90}$ values were calculated using a probit analysis (PASW statistics 18, 2009, SPSS Inc, Chicago, IL).

2.5. Algae Toxicity Tests. The acute ( $72 \mathrm{hrs})$ toxicity tests of the AgNMs were conducted on Raphidocelis subcapitata, ATCC 22662 (formerly known as Pseudokirchneriella subcapitata and Selenastrum capricornutum) in accordance with standard OECD guideline number 201 (freshwater alga and cyanobacteria, growth inhibition test) [20].

Algal cells in the exponential growth phase were used for all the experiments. At the start of each experiment 10,000 cells $/ \mathrm{mL}$ were added to $100 \mathrm{~mL}$ of each test medium under sterile conditions. The $\mathrm{pH}$ of the prepared culture media was first adjusted to a final value of $7.32 \pm 0.06$ using $0.1 \mathrm{~N} \mathrm{NaOH}$ or $0.1 \mathrm{~N} \mathrm{HCl}$ solutions. Each growth-inhibition test consisted of 6 AgNPs and AgNWs test concentrations (8, 4, 2, 1, 0.5, and $0.25 \mathrm{mg} / \mathrm{L})$ with triplicate for each concentration. Triplicate control groups (0 mg/L AgNPs and AgNWs) and triplicate vehicle control groups ( $0.24 \%$ IPA) were used for comparison. The test vessels were incubated for $72 \mathrm{hrs}$ under continuous illumination (5.44 $\pm 0.53 \mathrm{lux})$ at a constant temperature of $24^{\circ} \mathrm{C}$ in an automatic shaking incubator with illumination. After 24, 48, and $72 \mathrm{~h}$ of exposure, the cell density (biomass) for each treatment was determined using a particle counter, while the values for the logarithmic growth rate $(Y)$, biomass at time $t(X t)$, percent inhibition of yield (Iy), mean value for yield in the control group (Yc), value for yield for the treatment replicate $(\mathrm{Yt})$, average specific growth rate from time 0 to $72 \mathrm{hr}\left(\mu_{0-72}\right)$, mean value for the average specific growth rate in the control group $\left(\mu_{c}\right)$, average specific growth rate for the treatment replicate $\left(\mu_{t}\right)$, and percent inhibition of the average specific growth rate (Ir) were all obtained using the following formulas:

$$
\begin{gathered}
Y=X_{72}-X_{0} \\
\text { \%Iy }=\left\{\frac{(\mathrm{Yc}-\mathrm{Yt})}{\mathrm{Yc}}\right\} \times 100 \\
\mu_{0-72}=\frac{\left(\ln X_{72}-\ln X_{0}\right)}{72} \\
\text { \%Ir }=\left\{\frac{\left(\mu_{c}-\mu_{t}\right)}{\mu_{c}}\right\} \times 100 .
\end{gathered}
$$

The $\mathrm{EC}_{50}$ values were calculated using a probit analysis (PASW statistics 18, 2009, SPSS Inc., Chicago, IL). In addition, the morphology of the algal cells was observed following each treatment and categorized as normal (NOR), swollen (SWO), flocculated (FLC), decolored (DEC), ruptured (RUP), and/or atrophied (ATR).

2.6. Statistical Analysis. Data of all experiment were analyzed using the PASW statistic (Ver. 18, 2009, SPSS Inc., Chicago, IL, USA) and presented as mean \pm standard deviation. The $\mathrm{LC}_{50}$ values of fish test during $96 \mathrm{hrs}, \mathrm{EC}_{50}$ values of daphnia $48 \mathrm{hrs}$ and alga $72 \mathrm{hrs}$ were calculated by a probit analysis method. Comparison of nominal and actual concentrations of silver in fish toxicity test after $3 \mathrm{hrs}$ versus $96 \mathrm{hrs}$ was performed using Student's $t$-test. Difference were considered statistically significant when ${ }^{*} P<0.05$.

\section{Results}

3.1. Particle Characterization. The AgNPs and AgNWs size and distribution were measured by DLS before aquatic toxicity test. Figure 1 shows the hydrodynamic size distribution of colloidal AgNPs and AgNWs diluted in DI water. Figure 1(a) shows the hydrodynamic size distribution of AgNPs by intensity, and the size of AgNPs was distributed up to $10 \mathrm{~nm}$ with mean hydrodynamic diameter $2.36 \mathrm{~nm}$. Figure 1(b) shows hydrodynamic size distribution of AgNWs with mean diameter $2.1 \mu \mathrm{m}$.

In the case of the AgNWs diluted in fish test media (dechlorinated tap water) observed by TEM (Figures 2(a) and 2(b)), the count median length (CML) and geometric standard deviation (GSD) of the wires were $7.4 \mu \mathrm{m}$ and 1.5 , respectively (Figure 4(a)). The average diameter and standard deviation (SD) of the AgNW in TEM images were 57.01 \pm $1.2 \mathrm{~nm}$. Since the AgNPs and AgNWs preparations were in liquid, it was not possible to measure Brunauer Emmett and Teller (BET) surface area. Thus the average surface area measured from TEM image of the AgNWs was $6.37 \times 10^{18} \mathrm{~nm}^{2} / \mathrm{g}$.

In the case of the AgNPs diluted in fish test media observed by TEM, the particles were spherical in shape (Figures 3(a) and 3(b)), with a count median diameter (CMD) 


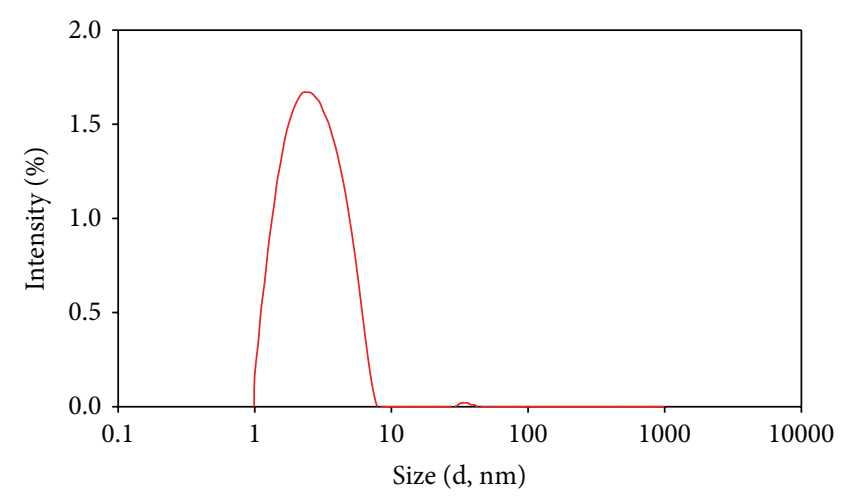

(a)

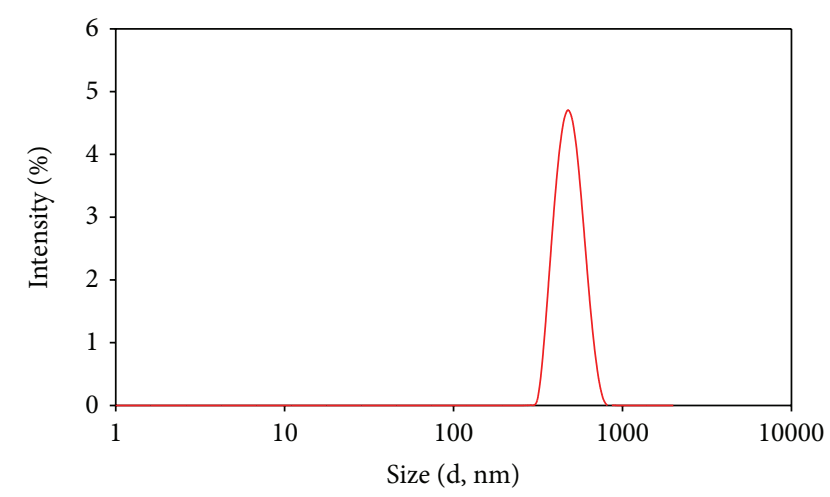

(b)

Figure 1: Size distribution of the AgNPs ((a) $5 \mathrm{mg} / \mathrm{L}$ ) and AgNWs ((b) $100 \mathrm{mg} / \mathrm{L}$ ) by DLS (d hydrodynamic diameter).

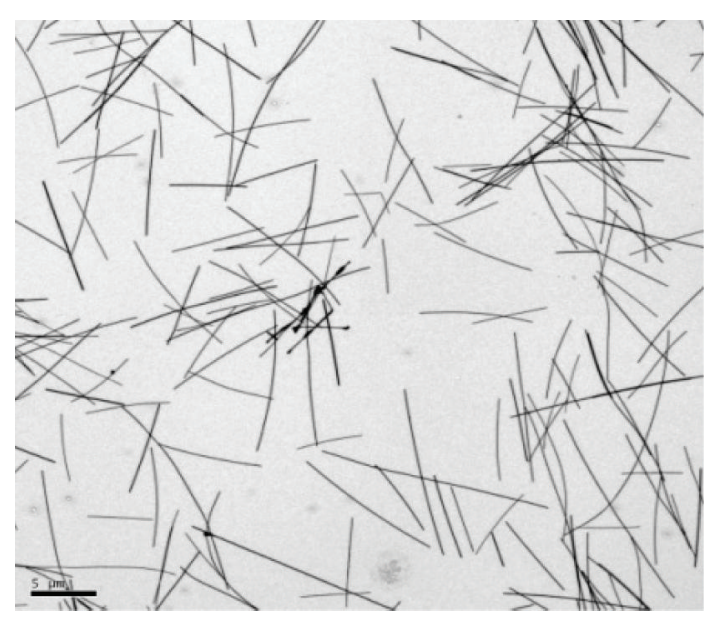

(a)

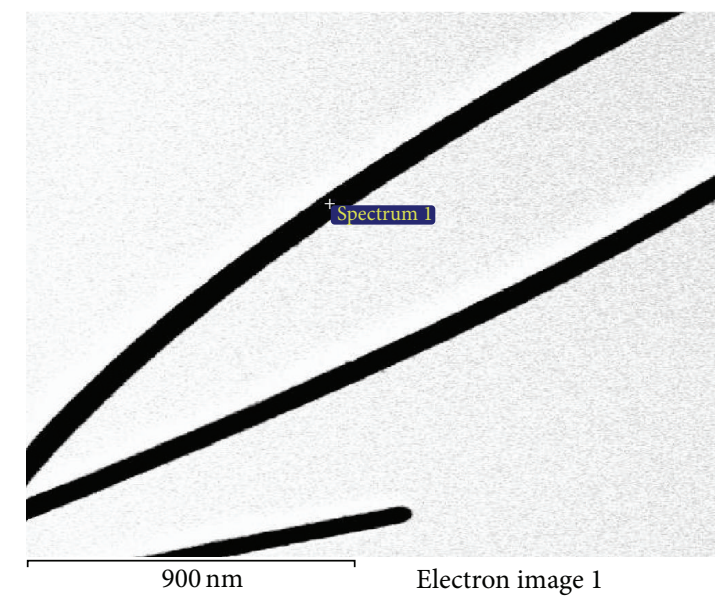

(c)

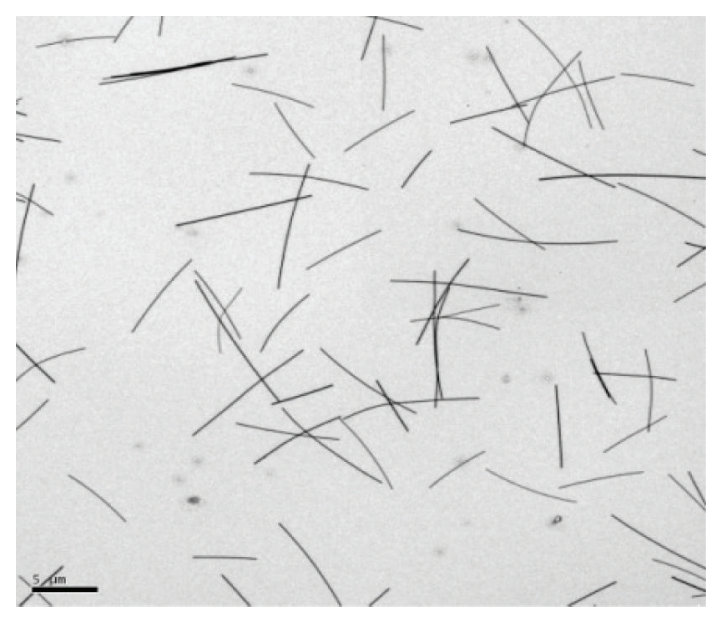

(b)

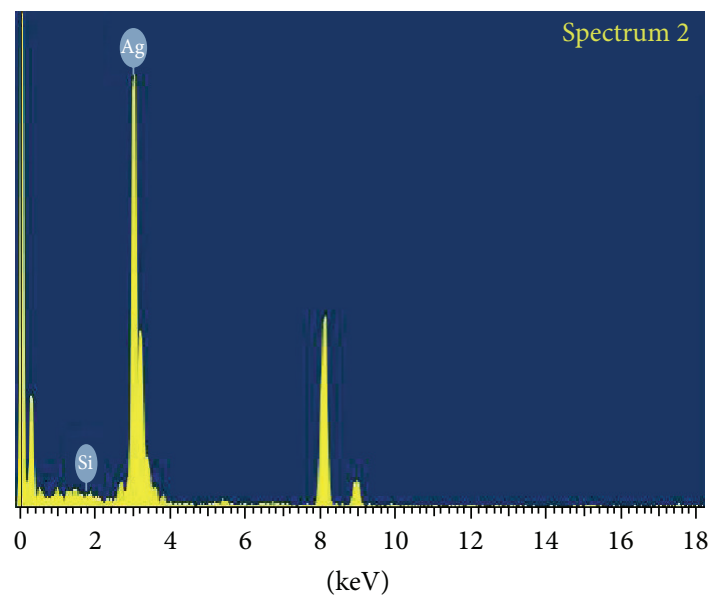

Full scale 902 cts cursor: 0.000

(d)

Figure 2: AgNWs, (a)-(b) TEM morphology and (c)-(d) EDX spectrometer pattern. 


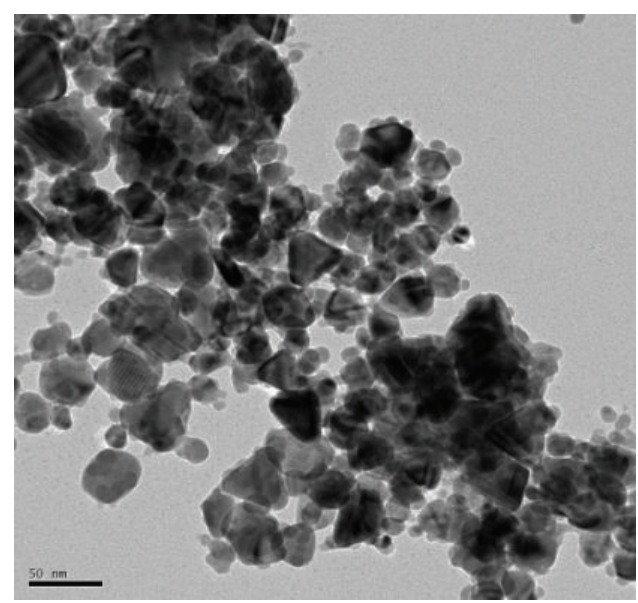

(a)

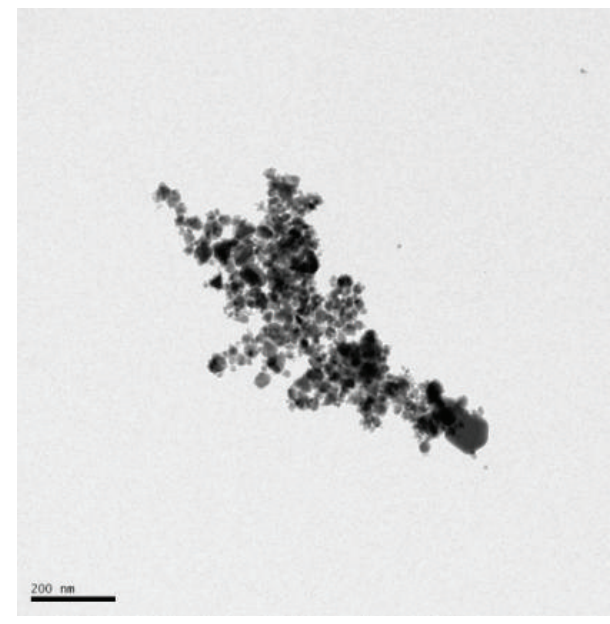

(c)

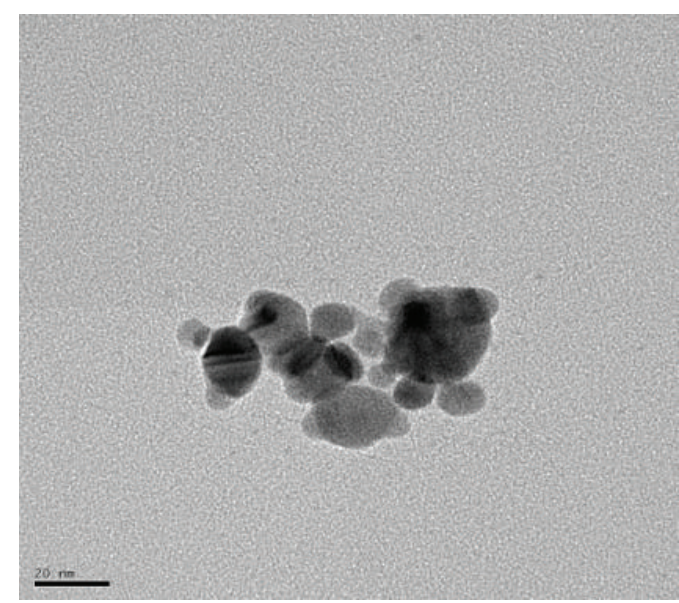

(b)

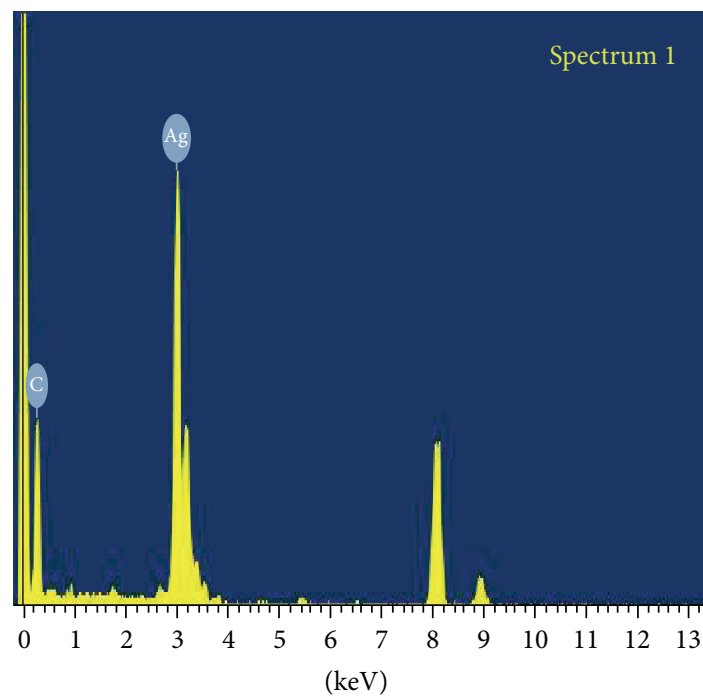

Full scale 1216 cts cursor: 0.000

(d)

FIgure 3: AgNPs, (a)-(b) TEM morphology and (c)-(d) EDX spectrometer pattern. The scale bar in (a) indicates $50 \mathrm{~nm}$, (b) for $20 \mathrm{~nm}$ and (c) for $200 \mathrm{~nm}$.

of $35 \mathrm{~nm}$ (Figure 4(b)). Plus, the GSD of the colloidal AgNPs was 1.4. The average measured surface area of the AgNPs was $1.63 \times 10^{19} \mathrm{~nm}^{2} / \mathrm{g}$ (more 2-fold greater than the average surface area of the AgNWs).

As seen in Figures 2(c), 2(d), 3(c) and 3(d), the energy dispersive X-ray (EDX) analyses revealed the presence of elemental silver in both AgNWs and AgNPs colloids.

\subsection{Silver Concentrations in Test Suspensions for Fish Toxicity} Testing. The concentrations of AgNPs and AgNWs in the test suspensions were determined after 3- and 96-hour test period. After $3 \mathrm{hrs}$, the concentrations of silver in the nanoparticle and nanowire suspensions were well maintained with only a slight deviation from the nominal concentrations (Table 1(a)). However, after $96 \mathrm{hrs}$, the silver concentrations showed a higher deviation from the nominal concentrations and silver concentrations after $3 \mathrm{hrs}$ (Table 1(b)). This greater deviation was due to agglomeration/aggregation or precipitation of the AgNPs and AgNWs.

3.3. Toxicity of AgNMs in Fish. During the experiments, the mean and SD of the water $\mathrm{pH}$, temperature, and dissolved oxygen in the exposure tanks were $7.85 \pm 0.13,21.7 \pm$ $0.61^{\circ} \mathrm{C}$, and $8.8 \pm 0.17 \mathrm{mg} / \mathrm{L}$, respectively. No mortality was observed either in the control or the vehicle control during the experimental period. The average 96-hour median lethal concentrations $\left(\mathrm{LC}_{50}\right)$ of AgNPs and AgNWs for Oryzias latipes were estimated to be 1.8 and $4.18 \mathrm{mg} / \mathrm{L}$, respectively. From these results, the $\mathrm{LC}_{50}$ proportion of AgNWs to AgNPs was 2.32, indicating AgNPs were estimated to be 2.32 times more toxic than the AgNWs for Oryzias latipes. Although signs of AgNPs accumulation were visible in fish gills, no apparent accumulation was detected after AgNWs exposure (Figure 5). 


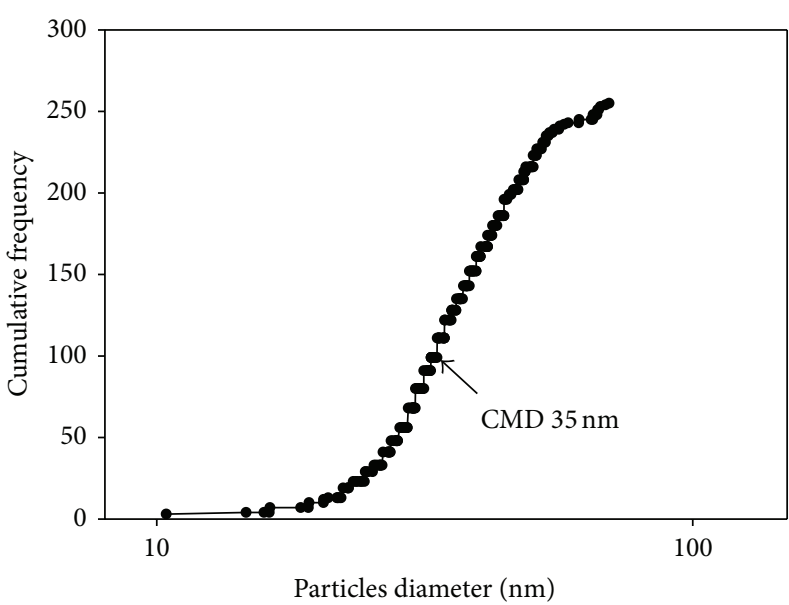

(a) AgNPs

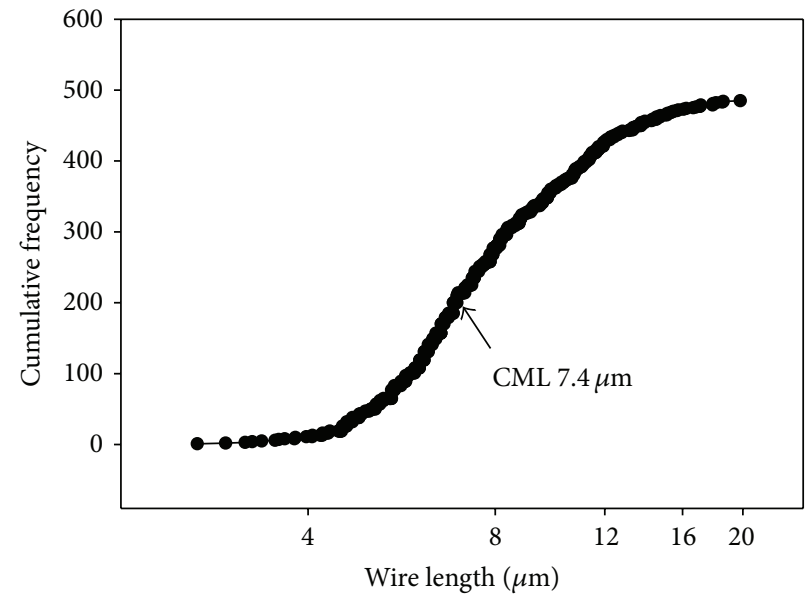

(b) AgNWs

FIGURE 4: Size distribution of wires/particles based on cumulative frequency determined from transmission electron microscope data for (a) AgNPs and (b) AgNWs.

TABLE 1: Nominal and actual concentrations of silver during fish toxicity testing.

(a) AgNWs

\begin{tabular}{llcccccc}
\hline Nominal concentration $(\mathrm{mg} / \mathrm{L})$ & 0 & 0.313 & 0.625 & 1.250 & 2.5 & 5 & 10 \\
Actual concentration after $3 \mathrm{hr}$ & 0 & $0.37 \pm 0.05$ & $0.71 \pm 0.03$ & $1.10 \pm 0.04$ & $3.68 \pm 0.53$ & $7.34 \pm 0.68$ & $12.39 \pm 1.10$ \\
Actual concentration after $96 \mathrm{hr}$ & 0 & $0.31 \pm 0.04$ & $0.55 \pm 0.06^{* *}$ & $0.93 \pm 0.06^{* *}$ & $3.06 \pm 0.24$ & $5.35 \pm 0.56^{* *}$ & $11.34 \pm 0.63$ \\
\hline
\end{tabular}

${ }^{* *} P<0.01,3 \mathrm{hr}$ versus $96 \mathrm{hr}$ by Student's $t$-test. Data are presented as mean \pm standard deviation.

(b) AgNPs

\begin{tabular}{|c|c|c|c|c|c|c|c|}
\hline Nominal concentration (mg/L) & 0 & 0.313 & 0.625 & 1.250 & 2.5 & 5 & 10 \\
\hline Actual concentration after $3 \mathrm{hr}(n=3)$ & 0 & $0.32 \pm 0.02$ & $0.53 \pm 0.04$ & $1.03 \pm 0.06$ & $2.27 \pm 0.31$ & $4.89 \pm 0.43$ & $10.29 \pm 0.51$ \\
\hline Actual concentration after $96 \mathrm{hr}(n=3)$ & 0 & $0.24 \pm 0.02^{* *}$ & $0.66 \pm 0.05^{*}$ & $0.82 \pm 0.07^{*}$ & $1.99 \pm 0.25$ & $4.13 \pm 0.48$ & $8.26 \pm 0.78^{*}$ \\
\hline
\end{tabular}

${ }^{*} \mathrm{P}<0.05,3 \mathrm{hr}$ versus $96 \mathrm{hr} ;{ }^{* *} \mathrm{P}<0.01,3 \mathrm{hr}$ versus $96 \mathrm{hr}$ by Student's $t$-test. Data are presented as mean \pm standard deviation.

TABLE 2: Effective concentration (EC) values of AgNPs and AgNWs for Daphnia magna neonates during 48 hrs.

\begin{tabular}{lccc}
\hline Nanomaterial & $\begin{array}{c}\text { Average } \mathrm{EC}_{10} \\
(\mathrm{mg} / \mathrm{L})\end{array}$ & $\begin{array}{c}\text { Average } \mathrm{EC}_{50} \\
(\mathrm{mg} / \mathrm{L})\end{array}$ & $\begin{array}{c}\text { Average } \mathrm{EC}_{90} \\
(\mathrm{mg} / \mathrm{L})\end{array}$ \\
\hline AgNWs & 0.117 & 0.139 & 0.160 \\
AgNPs & 0.007 & 0.012 & 0.017 \\
\hline
\end{tabular}

3.4. Toxicity of AgNMs in Daphnia. During the exposure period, the control groups showed zero mortality for all the experiments. The average values of the effective concentrations are shown in Table 2. The median effective concentrations $\left(\mathrm{EC}_{50} \mathrm{~s}\right)$ of AgNPs and AgNWs were calculated as 0.012 and $0.139 \mathrm{mg} / \mathrm{L}$, respectively. From these results, the $\mathrm{EC}_{50}$ proportion of AgNWs to AgNPs was 11.58, meaning the AgNPs were estimated to be 11.58 times more toxic than the AgNWs for Daphnia magna.

The normal and abnormal swimming of the live Daphnia are summarized in Table 3. For all the control and vehicle control groups, $100 \%$ of the live Daphnia exhibited completely normal swimming. For the AgNWs treatments, at concentrations up to $0.080 \mathrm{mg} / \mathrm{L}, 100 \%$ of the live Daphnia exhibited normal swimming, while at 0.16 and $0.32 \mathrm{mg} / \mathrm{L}$, $90 \%$ and $100 \%$ of the Daphnia exhibited abnormal swimming, respectively. All the abnormalities in the AgNWs groups were related to erratic swimming (ERR). Meanwhile, for the AgNPs treatments, at concentrations of 0.0059 and lower, all the Daphnia exhibited normal swimming, whereas, at higher concentrations (0.0082 and $0.0115 \mathrm{mg} / \mathrm{L})$, the Daphnia started to exhibit abnormal swimming, and, at $0.0161 \mathrm{mg} / \mathrm{L}$, all the Daphnia exhibited abnormal swimming. Most of the abnormalities in the AgNPs groups were related to erratic swimming (ERR), although $10 \%$ of the abnormal Daphnia at $0.0115 \mathrm{mg} / \mathrm{L}$ were mainly at the bottom (BOT). No Daphnia mainly at the surface (SUR) were observed in this study.

A notable phenomenon with the AgNPs treatments was the appearance of small bubbles under the carapace of the Daphnia (Figure 6(b)). This pigmentation became visible in parts of the brood chamber that was not observed in the controls (Figure 6(b)); this pigmentation may have been a sign of nanoparticle accumulation under the carapace. As regards the AgNWs treatments, large amounts of ingested nanowires were found in the gut tract of the Daphnia (Figure 6(c)). 


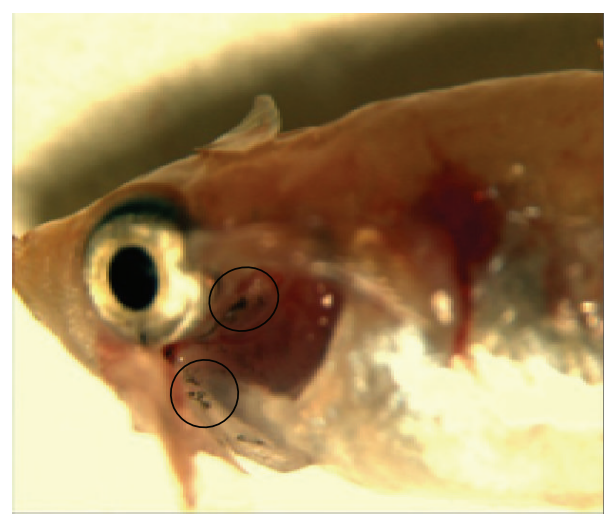

(a)

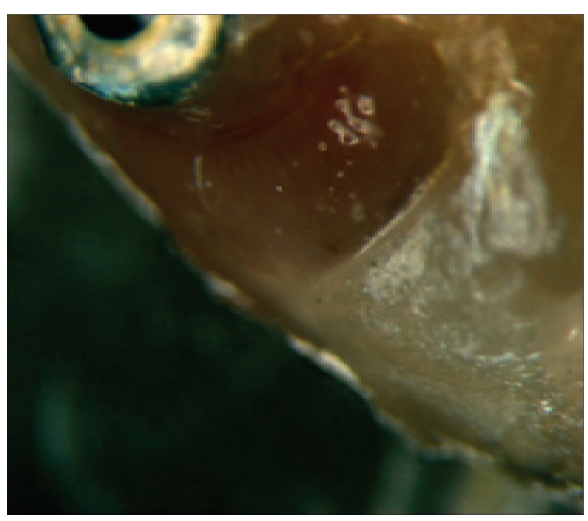

(b)

FIgURE 5: (a) Signs of AgNPs accumulation on fish gills during $96 \mathrm{hr}$. (b) No visible accumulation of AgNWs. The circles indicate accumulation of AgNPs on the fish gill.

TABLE 3: Percentage of normal (NOR) and abnormal (ABN) Daphnia magna neonates during 48-hour exposure to AgNPs and AgNWs. ERR: erratic swimming, BOT: Daphnia mainly at the bottom, and SUR: Daphnia mainly at the surface.

\begin{tabular}{|c|c|c|c|c|c|c|}
\hline Nanomaterial & Conc. (mg/L) & $\%$ NOR & $\% \mathrm{ABN}$ & $\%$ ERR & $\% \mathrm{BOT}$ & $\%$ SUR \\
\hline \multirow{9}{*}{ AgNWs } & (Control) 0 & 100 & 0 & 0 & 0 & 0 \\
\hline & Vehicle control & 100 & 0 & 0 & 0 & 0 \\
\hline & 0.005 & 100 & 0 & 0 & 0 & 0 \\
\hline & 0.010 & 100 & 0 & 0 & 0 & 0 \\
\hline & 0.020 & 100 & 0 & 0 & 0 & 0 \\
\hline & 0.040 & 100 & 0 & 0 & 0 & 0 \\
\hline & 0.080 & 100 & 0 & 0 & 0 & 0 \\
\hline & 0.160 & 10 & 90 & 90 & 0 & 0 \\
\hline & 0.320 & 0 & 100 & 100 & 0 & 0 \\
\hline \multirow{7}{*}{ AgNPs } & (Control) 0 & 100 & 0 & 0 & 0 & 0 \\
\hline & 0.0030 & 100 & 0 & 0 & 0 & 0 \\
\hline & 0.0042 & 100 & 0 & 0 & 0 & 0 \\
\hline & 0.0059 & 100 & 0 & 0 & 0 & 0 \\
\hline & 0.0082 & 25 & 75 & 75 & 0 & 0 \\
\hline & 0.0115 & 30 & 70 & 60 & 10 & 0 \\
\hline & 0.0161 & 0 & 100 & 100 & 0 & 0 \\
\hline
\end{tabular}

3.5. Toxicity of AgNMs in Alga. The growth inhibition of the cell biomass of Raphidocelis subcapitata during $72 \mathrm{hrs}$ of exposure to different concentrations of AgNWs and AgNPs are shown in Figure 7. The cell biomass increase rate, logarithmic growth rate, average specific growth rate, percent of yield inhibition, and percent of average specific growth rate inhibition are all summarized in Table 4 and Figure 8, satisfying the validity of the test prescribed in the OECD Test guideline 201 [20]. The OECD 201 states that the biomass in the control cultures should be increased more than 16 -fold within the 72-hour test period, and the mean coefficient of variation for section-by-section specific growth rates in the control culture should not exceed $35 \%$ in alga test. Also, the coefficient of variation of average specific growth rates during the whole test period in replicate control culture should not exceed $7 \%$ in alga tests. The inhibitory rates increased when increasing the concentrations of AgNMs. While all the cells in the control groups retained a normal appearance, AgNWs and AgNPs concentration of $0.25 \mathrm{mg} / \mathrm{L}$ resulted in flocculation and $0.5 \mathrm{mg} / \mathrm{L}$ and higher concentrations resulted in flocculation, depolarization, rupture, and atrophy. None of the AgNWs and AgNPs concentrations produced any swelling.

The average values for the median effective concentrations $\left(\mathrm{EC}_{50}\right)$, no observed effect concentrations (NOEC), and lowest observed effect concentrations (LOEC) are shown in Table 5. The 72 hrs $\mathrm{EC}_{50}$ (concentration at which a $50 \%$ inhibition of the growth rate is observed) of AgNWs and AgNPs for the average specific growth rate of Raphidocelis subcapitata was calculated as $2.573 \mathrm{mg} / \mathrm{L}$ and $0.74 \mathrm{mg} / \mathrm{L}$, respectively.

\section{Discussion}

The AgNMs were characterized using DLS and TEM. The measured AgNPs by DLS obtained that result is similar to information provided by the manufacturer (Figure 1(a)). In 


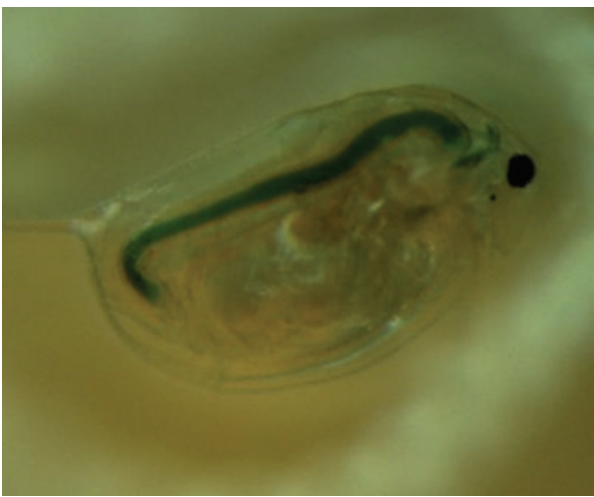

(a)

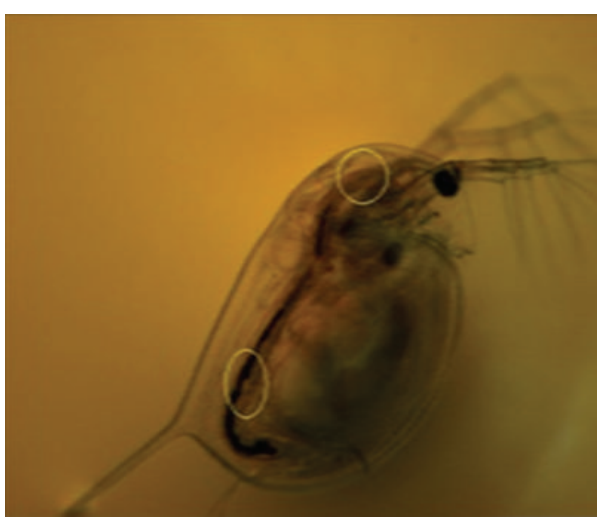

(c)

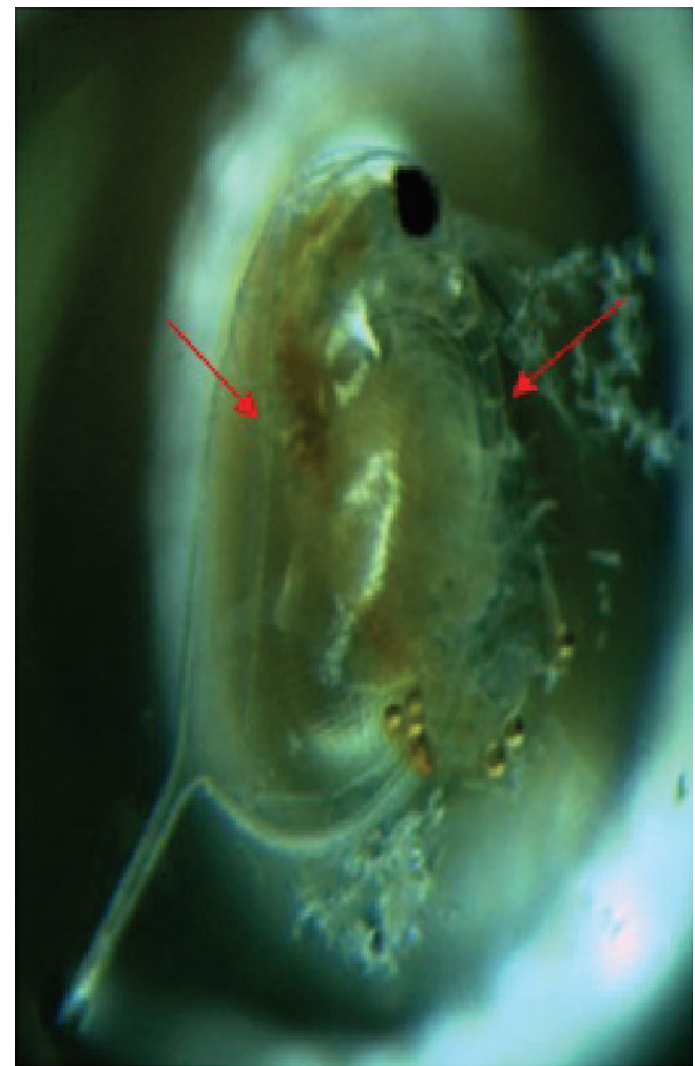

(b)

Figure 6: Microscope images of (a) control Daphnia fed with chlorella, (b) Daphnia exposed to AgNPs, and (c) Daphnia exposed to AgNWs. The arrows of (b) indicate accumulation of AgNP in the gut (left) and on the antenna (right) of Daphnia magna. The circles of (c) indicate accumulation of AgNWs in the gut of Daphnia magna.

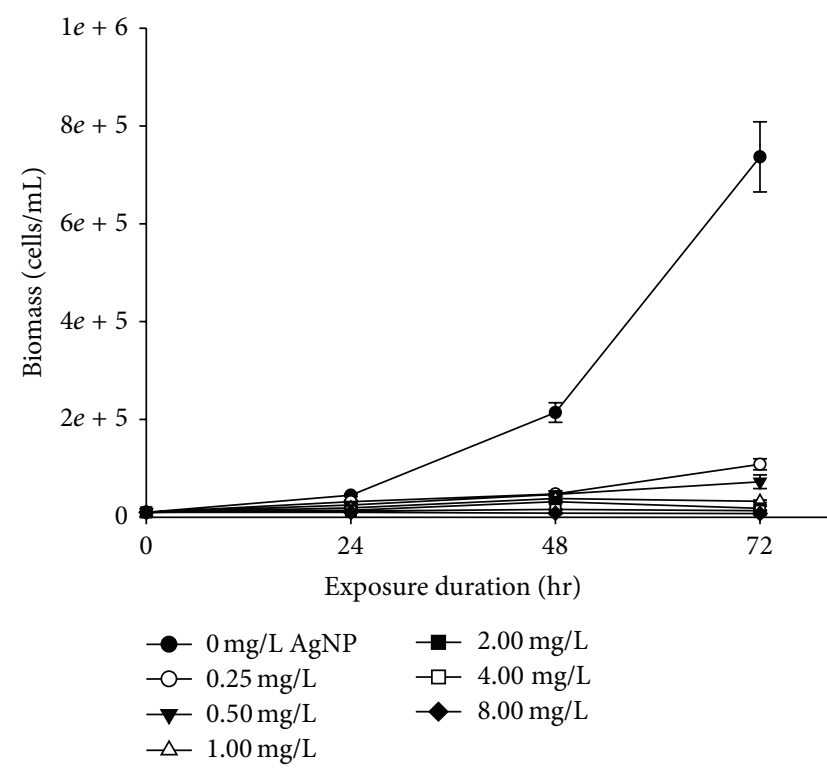

(a) AgNPs

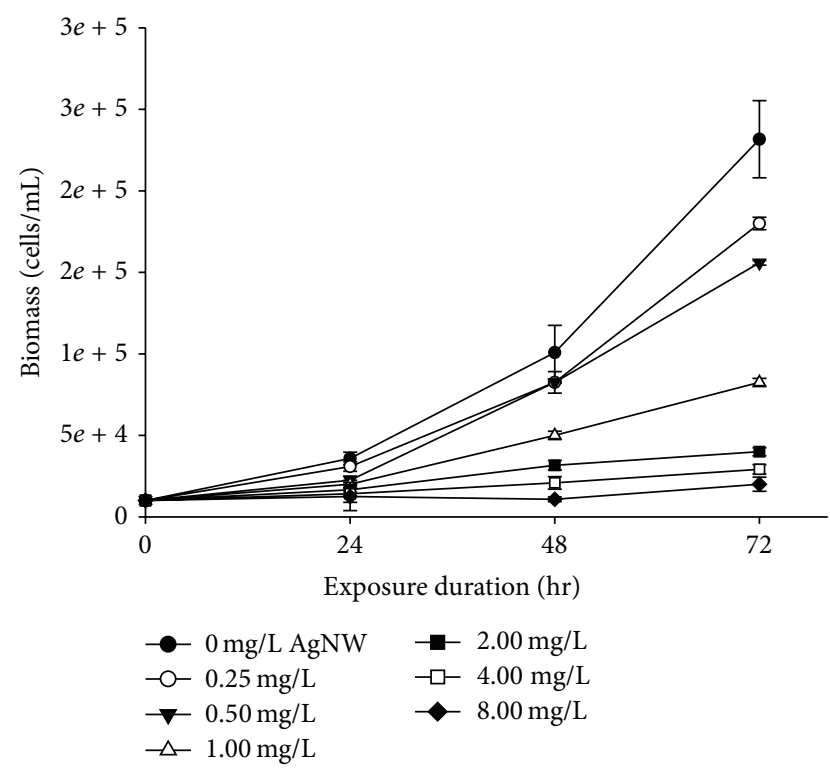

(b) AgNWs

FIgURE 7: Growth inhibition of biomass caused by AgNWs and AgNPs. Error bars indicate standard deviation. 


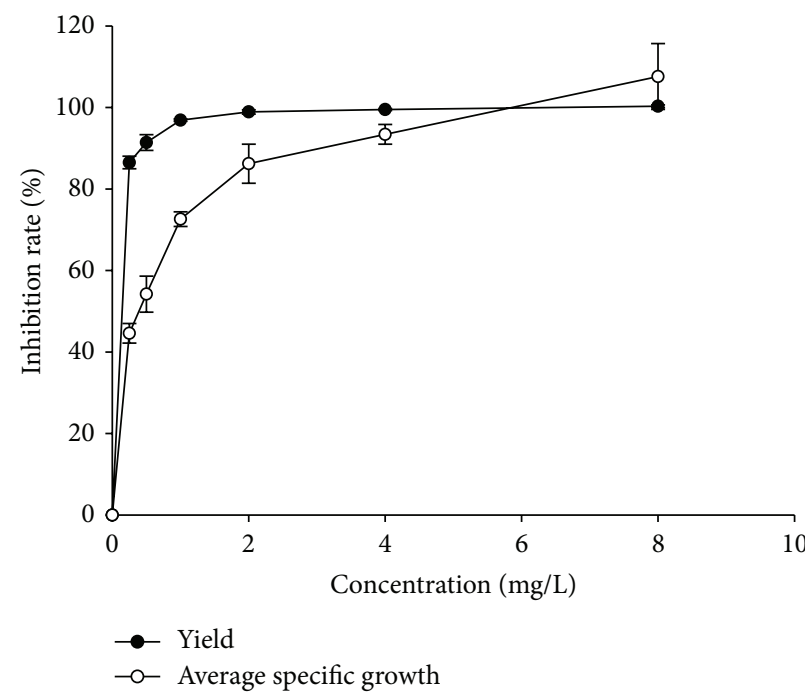

(a) AgNPs

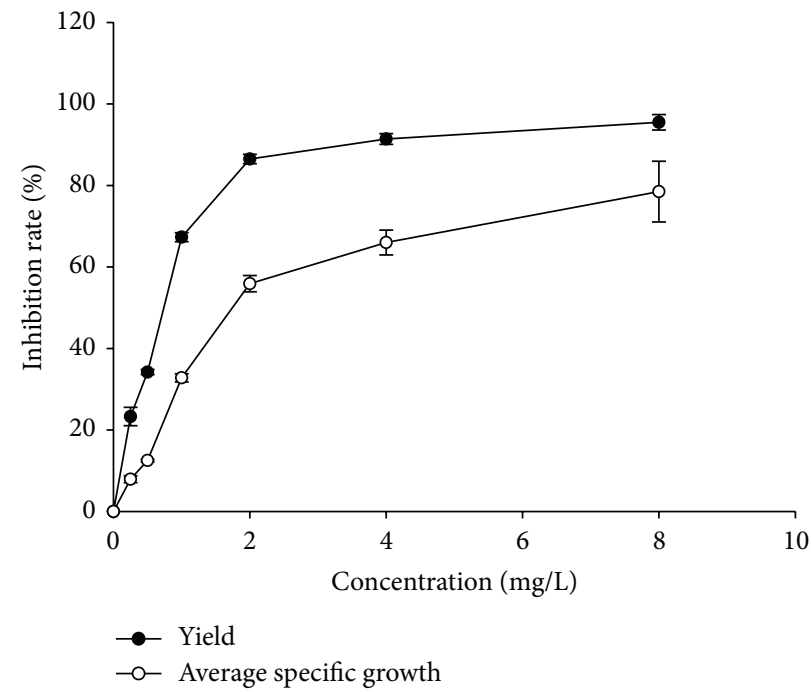

(b) AgNWs

FIGURE 8: Inhibition rate of average specific growth and yield. Error bars indicate standard deviation.

TABLE 4: Rate of biomass increase, average specific growth rate, and yield inhibition of algal cells during 72-hour exposure to different concentrations of AgNWs and AgNPs.

\begin{tabular}{|c|c|c|c|c|c|c|}
\hline NMs & Conc. $(\mathrm{mg} / \mathrm{L})$ & Rate of cell biomass increase & $Y^{\mathrm{a}}$ & $\% \mathrm{Iy}^{\mathrm{b}}$ & $\mu_{0-72^{\mathrm{c}}}$ & $\% \operatorname{Ir}^{\mathrm{d}}$ \\
\hline \multirow{8}{*}{ AgNWs } & Control (0) & $22.25 \pm 2.47$ & 221,660 & 0 & $0.043 \pm 0.001$ & 0 \\
\hline & Vehicle control & $18.6 \pm 1.50$ & 175,830 & 20.7 & $0.040 \pm 0.001$ & 6.98 \\
\hline & 0.25 & $18 \pm 0.5$ & 170,000 & 23.3 & $0.040 \pm 0.000$ & 7.93 \\
\hline & 0.5 & $15.56 \pm 0.11$ & 145,833 & 34.2 & $0.038 \pm 0.000$ & 12.5 \\
\hline & 1 & $8.23 \pm 0.25$ & 72,500 & 67.3 & $0.029 \pm 0.000$ & 32.8 \\
\hline & 2 & $3.96 \pm 0.25$ & 30,000 & 86.5 & $0.019 \pm 0.000$ & 55.9 \\
\hline & 4 & $3.03 \pm 0.28$ & 19,167 & 91.4 & $0.014 \pm 0.001$ & 66 \\
\hline & 8 & $1.5 \pm 1.21$ & 5,500 & 97.5 & $-0.001 \pm 0.021$ & 103 \\
\hline \multirow{7}{*}{ AgNPs } & Control (0) & $73.67 \pm 7.17$ & 726,667 & 0 & $0.060 \pm 0.001$ & 0 \\
\hline & 0.25 & $10.83 \pm 1.13$ & 98,333 & 86.5 & $0.033 \pm 0.001$ & 44.6 \\
\hline & 0.5 & $7.25 \pm 1.39$ & 62,500 & 91.4 & $0.027 \pm 0.003$ & 54.2 \\
\hline & 1 & $3.25 \pm 0.25$ & 22,500 & 96.9 & $0.016 \pm 0.001$ & 72.6 \\
\hline & 2 & $1.83 \pm 0.38$ & 8,333 & 98.9 & $0.008 \pm 0.003$ & 86.2 \\
\hline & 4 & $1.33 \pm 0.14$ & 3,333 & 99.5 & $0.004 \pm 0.001$ & 93.4 \\
\hline & 8 & $0.75 \pm 0.25$ & $-2,500$ & 100.3 & $-0.005 \pm 0.004$ & 107.6 \\
\hline
\end{tabular}

$Y^{\mathrm{a}}$ : logarithmic growth rate; $\% \mathrm{Iy}^{\mathrm{b}}$ : percent of yield inhibition; $\mu_{0-72^{\mathrm{c}}}$ : average specific growth rate from time 0 to $72 ; \% \mathrm{Ir}^{\mathrm{d}}:$ percent of average specific growth rate inhibition. Data are presented as mean \pm standard deviation.

TABLE 5: Values of median effective concentration $\left(\mathrm{EC}_{50}\right)$, no observed effect concentration (NOEC), and lowest observed effect concentration (LOEC) of AgNWs and AgNPs for Raphidocelis subcapitata during $72 \mathrm{hrs.}$

\begin{tabular}{|c|c|c|c|c|c|c|c|c|}
\hline \multirow[b]{2}{*}{ NMs } & \multicolumn{4}{|c|}{ Yield } & \multicolumn{4}{|c|}{ Average specific growth rate } \\
\hline & $\mathrm{EC}_{50}(\mathrm{mg} / \mathrm{L})$ & $\begin{array}{l}\text { 95\% confidence } \\
\text { limits }(\mathrm{mg} / \mathrm{L})\end{array}$ & $\begin{array}{l}\text { NOEC } \\
(\mathrm{mg} / \mathrm{L})\end{array}$ & $\begin{array}{c}\mathrm{LOEC} \\
(\mathrm{mg} / \mathrm{L})\end{array}$ & $\begin{array}{l}\mathrm{EC}_{50} \\
(\mathrm{mg} / \mathrm{L})\end{array}$ & $\begin{array}{l}\text { 95\% confidence } \\
\text { limits }(\mathrm{mg} / \mathrm{L})\end{array}$ & $\begin{array}{l}\text { NOEC } \\
(\mathrm{mg} / \mathrm{L})\end{array}$ & $\begin{array}{l}\text { LOEC } \\
(\mathrm{mg} / \mathrm{L})\end{array}$ \\
\hline AgNWs & 1.22 & - & - & 0.25 & 2.57 & $1.55 \sim 6.05$ & 0.25 & 1.00 \\
\hline AgNPs & 0.14 & & & 0.25 & 0.74 & & & 0.25 \\
\hline
\end{tabular}


case of AgNWs, that result is slightly different from the information provided by the manufacturer (Figure 1(b)). Hydrodynamic diameter measured by DLS could be appropriate for spherical with monodispersed particles [21]. DLS has been used to measure particle size distribution of multiwall carbon nanotubes [22], although the size distribution is not exactly comparable to TEM size distribution. In this study TEM and DLS size are compared. As expected, particle size by DLS, which measures hydrodynamic size, is larger than TEM size.

This study demonstrated that AgNPs and AgNWs are both toxic to fresh water organisms, including fish (Oryzias latipes), water fleas (Daphnia magna), and algae (Raphidocelis subcapitata). Based on the present results, the calculated $\mathrm{LC}_{50}$ or $\mathrm{EC}_{50}$ of $\mathrm{AgNPs}$ for the fish, daphnia, and algae were about 2.3-, 11.5-, and 3.5-fold lower, respectively, than the corresponding values of AgNWs. Thus, AgNPs would seem to be more toxic to aquatic organisms than AgNWs, at least in freshwater media. Recent studies shown that the dissolved $\mathrm{Ag}^{+}$released from AgNPs and AgNWs plays a critical role in the aquatic toxicity of these nanomaterials [11, 23, 24]. Meanwhile, the degree of $\mathrm{Ag}^{+}$dissolution depends on the surface area of the nanoscale silver, and the present study showed that the average measured surface area of the AgNPs was more than 2-fold greater than that of the AgNWs. The amount of silver ions released from the surface of the AgNPs was greater than the amount of $\mathrm{Ag}^{+}$released from the surface of the AgNWs; thus the AgNPs logically displayed a greater toxicity to the aquatic organisms when compared with the AgNWs. In another recent study, Visnapuu et al. [25] found that the toxicity and bioavailability of AgNWs and AgNPs to $E$. coli depended on the dissolved silver ions with no shape-induced/related effects. Beer et al. [26] showed that free silver ions in AgNPs suspensions play a significant role in the toxicity of AgNPs suspensions to A549 lung cells. Overall, these results with our current observation indicate that silver ions released from particle or wire are toxicity determinants and surface area is major factor in releasing silver ions from particles and wires.

In contrast to the present results, Stoehr et al. [27] showed that silver wires (length: $1.5-25 \mu \mathrm{m}$; diameter $100-160 \mathrm{~nm}$ ) had a strong effect on A549 human lung epithelial cells, whereas PVP-coated spherical silver nanoparticles $(30 \mathrm{~nm})$ had no effect with a similar particle mass, surface area, and number concentration. In this case, the PVP coating may have reduced the release of $\mathrm{Ag}^{+}$from the AgNPs, thereby decreasing the toxicity at the tested concentrations, or the shape may have affected the toxicity, as observed with other high aspect ratio nanoparticles (HARN) [28, 29]. When the freshwater mussel Elliptio complanata was exposed to increasing concentrations of 20-nm AgNPs, 80-nm AgNPS, and dissolved $\mathrm{Ag}$ ions for $48 \mathrm{~h}$ at $15^{\circ} \mathrm{C}$, the response pattern of $80 \mathrm{~nm}$ AgNPS was more closely related to Ag ions than $20 \mathrm{~nm}$ AgNPs, suggesting a more important release of dissolved Ag ions from $80 \mathrm{~nm}$ AgNPs [30]. These results indicate that some more complicated toxic mechanisms for AgNPs are presented other than silver ion release from the surface of AgNPs or AgNWs.

The same abnormal swimming, brood chamber pigmentation, NM ingestion, and small bubbles under the carapace of the D. magna exposed to nanoscale silver observed in the current study were also previously reported by Asghari et al. [7] in the case of D. magna exposed to AgNPs. Further, Artal et al. [11] described an increase in the droplet size in Daphnia as a response to nanowire exposure that was similar to the bubbles observed in the present study. The large quantities of ingested AgNWs found in the gut tract of the Daphnia in the current study were similar to previous reports of the ingestion of other one-dimensional nanostructures that became trapped in the digestive tract $[11,31,32]$. As Daphnia are a major food source for many kinds of fish, aquatic insect larvae, and other invertebrates, their ingestion of nanomaterials represents a potential for subsequent transfer of nanomaterials to higher organisms via food chain.

In this paper, comparison is done on aquatic organism toxicity of AgNPs with AgNWs based on the OECD test guidelines 201, 202, and 203. In 2013, OECD Working Party on Manufactured Nanomaterials (WPMN) recommended their member countries to use OECD test guidelines in safety testing for nanomaterials after 6 years of OECD work on the safety of manufactured nanomaterials. Safety of nanomaterials can be addressed with existing test methods and assessment approaches, although some cases might be necessary to adapt methods of sample preparation and dosimetry of safety testing but not necessary to develop completely new approaches for nanomaterials [33]. Thus the test results for AgNPs and AgNWs based on the OECD test guidelines might be very useful in evaluating safety of nanomaterials. Current hazard classification used in the Globally Harmonized System of Classification and Labelling of Chemicals [34] is also based on the test results established on the OECD test guidelines.

According to the median lethal/effective concentrations of AgNWs and AgNPs estimated in the present study, the order of animal susceptibility was daphnia $>$ algae $>$ fish. Based on the GHS hazard classification, the AgNPs and AgNWs tested in this study should both be classified as "category acute 1" for D. magna and "category acute 2" for Oryzias latipes. Plus, the AgNWs and AgNPs should be classified as "category acute 2" and "category acute 1" for Raphidocelis subcapitata, respectively. Consequently, based on the current findings and the results of other published studies, AgNMs would appear to have a toxic effect on aquatic organisms, at least in freshwater environments; thus more attention should be paid to preventing their accidental or intentional release into aquatic ecosystems.

\section{Conflict of Interests}

The authors report no conflict of interests. The authors alone are responsible for the content and writing of this paper.

\section{Acknowledgment}

This research was supported by the Nanomaterial Technology Development Program (Green Nano Technology Development Program) through the National Research Foundation of Korea (NRF) funded by the Korean Ministry of Education, Science and Technology (no. 2011-0020090). 


\section{References}

[1] A. A. Keller, S. McFerran, A. Lazareva, and S. Suh, "Global life cycle releases of engineered nanomaterials," Journal of Nanoparticle Research, vol. 15, no. 6, article 1692, 2013.

[2] Woodrow Wilson Database, Nanotechnology Consumer Product Inventory, 2011, http://www.nanotechproject.org/inventories/ consumer/analysis_draft/.

[3] G. E. Batley, J. K. Kirby, and M. J. McLaughlin, "Fate and risks of nanomaterials in aquatic and terrestrial environments," Accounts of Chemical Research, vol. 46, no. 3, pp. 854-862, 2013.

[4] S. Prabhu and E. K. Poulose, "Silver nanoparticles: mechanism of antimicrobial action, synthesis, medical applications, and toxicity effects," International Nano Letters, vol. 2, no. 1, article 32, 2012.

[5] M. Valodkar, P. Sharma, D. K. Kanchan, and S. Thakore, "Conducting and antimicrobial properties of silver nanowirewaxy starch nanocomposites," International Journal of Green Nanotechnology: Physics and Chemistry, vol. 2, no. 1, pp. P10P19, 2010.

[6] S. A. Johari, M. R. Kalbassi, M. Soltani, and I. J. Yu, "Toxicity comparison of colloidal silver nanoparticles in various life stages of rainbow trout (Oncorhynchus mykiss)," Iranian Journal of Fisheries Sciences, vol. 12, no. 1, pp. 76-95, 2013.

[7] S. Asghari, S. A. Johari, J. H. Lee et al., "Toxicity of various silver nanoparticles compared to silver ions in Daphnia magna," Journal of Nanobiotechnology, vol. 10, article no. 14, 2012.

[8] F. Ribeiro, J. A. Gallego-Urrea, K. Jurkschat et al., "Silver nanoparticles and silver nitrate induce high toxicity to Pseudokirchneriella subcapitata, Daphnia magna and Danio rerio," Science of the Total Environment, vol. 466-467, pp. 232-241, 2014.

[9] S. George, S. Lin, Z. Ji et al., "Surface defects on plate-shaped silver nanoparticles contribute to its hazard potential in a fish gill cell line and zebrafish embryos," ACS Nano, vol. 6, no. 5, pp. 3745-3759, 2012.

[10] W.-Y. Kim, J. Kim, J. D. Park, H. Y. Ryu, and I. J. Yu, "Histological study of gender differences in accumulation of silver nanoparticles in kidneys of Fischer 344 rats," Journal of Toxicology and Environmental Health, Part A: Current Issues, vol. 72, no. 21-22, pp. 1279-1284, 2009.

[11] M. C. Artal, R. D. Holtz, F. Kummrow, O. L. Alves, and G. D. A. Umbuzeiro, "The role of silver and vanadium release in the toxicity of silver vanadate nanowires toward Daphnia similis," Environmental Toxicology and Chemistry, vol. 32, no. 4, pp. 908912, 2013.

[12] L. D. Scanlan, R. B. Reed, A. V. Loguinov et al., "Silver nanowire exposure results in internalization and toxicity to Daphnia magna," ACS Nano, vol. 7, no. 12, pp. 10681-10694, 2013.

[13] J. Y. Lee, J. S. Kim, K. H. An et al., "Electrophoretic and dynamic light scattering in evaluating dispersion and size distribution of single-walled carbon nanotubes," Journal of Nanoscience and Nanotechnology, vol. 5, no. 7, pp. 1045-1049, 2005.

[14] NIOSH (National Institute for Occupational Safety and Health), NIOSH Manual of Analytical Methods, (Method no. 7300, 7604), NIOSH, Cincinnati, Ohio, USA, 1999.

[15] P. G. Welsh, J. Lipton, C. A. Mebane, and J. C. A. Marr, "Influence of flow-through and renewal exposures on the toxicity of copper to rainbow trout," Ecotoxicology and Environmental Safety, vol. 69, no. 2, pp. 199-208, 2008.

[16] OECD, OECD Guidelines for the Testing of Chemicals. Test no. 203: Fish, Acute Toxicity Test, Organization for Economic Cooperation and Development, Paris, France, 1992.
[17] OECD, “Test No. 202: Daphnia sp., acute immobilization test," in OECD Guidelines for the Testing of Chemicals, Organization for Economic Cooperation and Development, Paris, France, 2004.

[18] H. J. Allen, C. A. Impellitteri, D. A. Macke et al., "Effects from filtration, capping agents, and presence/absence of food on the toxicity of silver nanoparticles to Daphnia magna," Environmental Toxicology and Chemistry, vol. 29, no. 12, pp. 2742-2750, 2010.

[19] C. N. Glover and C. M. Wood, "Accumulation and elimination of silver in Daphnia magna and the effect of natural organic matter," Aquatic Toxicology, vol. 73, no. 4, pp. 406-417, 2005.

[20] OECD, OECD Guidelines for the Testing of Chemicals. Test No. 201: Freshwater Alga and Cyanobacteria, Growth Inhibition Test, Organization for Economic Cooperation and Development, Paris, France, 2006.

[21] E. Tomaszewska, K. Soliwoda, K. Kadziola et al., "Detection limits of DLS and UV-Vis spectroscopy in characterization of polydisperse nanoparticles colloids," Journal of Nanomaterials, vol. 2013, Article ID 313081, 10 pages, 2013.

[22] J. S. Kim, K. Lee, Y. H. Lee et al., "Aspect ratio has no effect on genotoxicity of multi-wall carbon nanotubes," Archives of Toxicology, vol. 85, no. 7, pp. 775-786, 2011.

[23] A. J. Kennedy, M. S. Hull, A. J. Bednar et al., "Fractionating nanosilver: importance for determining toxicity to aquatic test organisms," Environmental Science \& Technology, vol. 44, no. 24, pp. 9571-9577, 2010.

[24] K. M. Newton, H. L. Puppala, C. L. Kitchens, V. L. Colvin, and S. J. Klaine, "Silver nanoparticle toxicity to Daphnia magna is a function of dissolved silver concentration," Environmental Toxicology and Chemistry, vol. 32, no. 10, pp. 2356-2364, 2013.

[25] M. Visnapuu, U. Joost, K. Juganson et al., "Dissolution of silver nanowires and nanospheres dictates their toxicity to Escherichia coli," BioMed Research International, vol. 2013, Article ID 819252, 9 pages, 2013.

[26] C. Beer, R. Foldbjerg, Y. Hayashi, D. S. Sutherland, and H. Autrup, "Toxicity of silver nanoparticles-Nanoparticle or silver ion?” Toxicology Letters, vol. 208, no. 3, pp. 286-292, 2012.

[27] L. C. Stoehr, E. Gonzalez, A. Stampfl et al., "Shape matters: effects of silver nanospheres and wires on human alveolar epithelial cells," Particle and Fibre Toxicology, vol. 8, article 36, 2011.

[28] C. A. Poland, R. Duffin, I. Kinloch et al., "Carbon nanotubes introduced into the abdominal cavity of mice show asbestoslike pathogenicity in a pilot study," Nature Nanotechnology, vol. 3, no. 7, pp. 423-428, 2008.

[29] C. L. Tran, S. M. Hankin, B. Ross et al., "An outline scoping study to determine whether high aspect ratio nanoparticles (HARN) should raise the same concerns as do asbestos fibres," Report on DEFRA Project CB0406, IOM (Institute of Occupational Medicine), Edinburgh, UK, 2008.

[30] F. Gagné, J. Auclair, P. Turcotte, and C. Gagnon, "Sublethal effects of silver nanoparticles and dissolved silver in freshwater mussels," Journal of Toxicology and Environmental Health-Part A: Current Issues, vol. 76, no. 8, pp. 479-490, 2013.

[31] A. P. Roberts, A. S. Mount, B. Seda et al., "In vivo biomodification of lipid-coated carbon nanotubes by Daphnia magna," Environmental Science and Technology, vol. 41, no. 8, pp. 30253029, 2007.

[32] E. J. Petersen, J. Akkanen, J. V. K. Kukkonen, and W. J. Weber Jr., "Biological uptake and depuration of carbon nanotubes by 
Daphnia magna," Environmental Science \& Technology, vol. 43, no. 8, pp. 2969-2975, 2009.

[33] OECD, Six Years of OECD Work on the Safety of Manufactured Nanomaterials, Organization for Economic Cooperation and Development, Paris, France, 2013, http://www.oecd.org/env/ ehs/nanosafety/.

[34] GHS, Globally Harmonized System of Classification and Labelling of Chemicals, United Nations Publications, New York, NY, USA, 4th edition, 2011. 

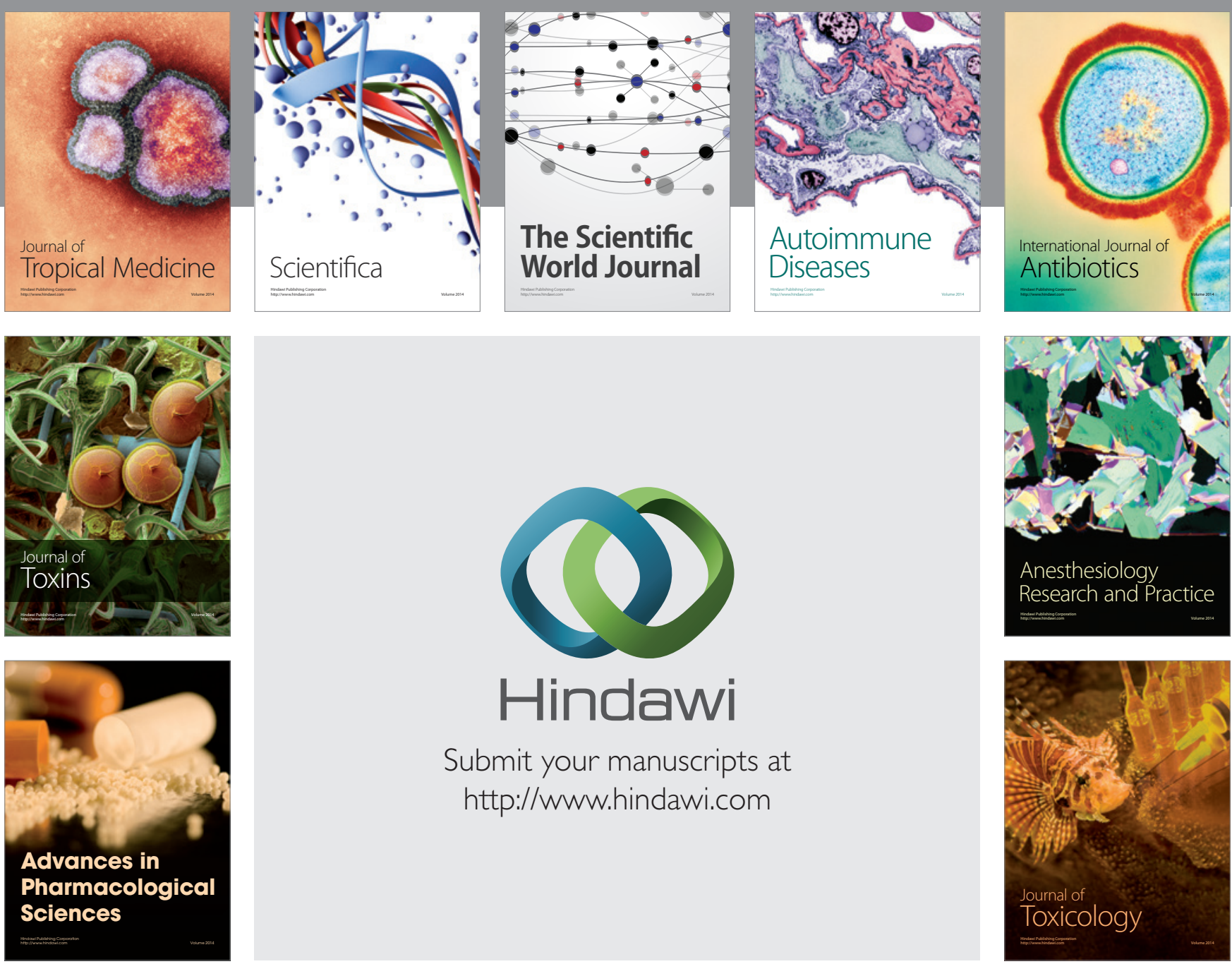

\section{Hindawi}

Submit your manuscripts at

http://www.hindawi.com
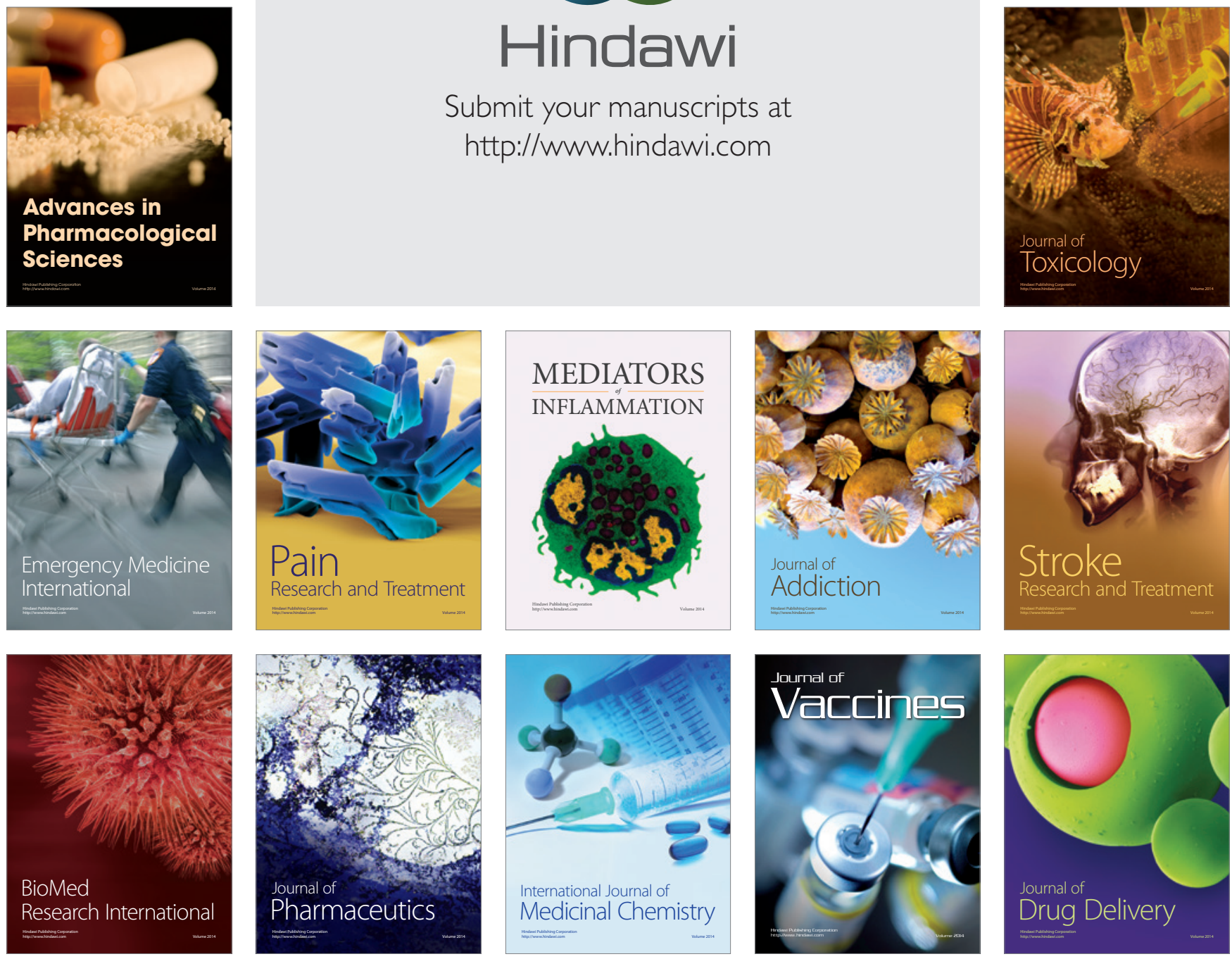